\title{
Commentary: In cardiac surgery, you are only as old as you feel
}

\author{
Michael C. Grant, MD, MSE
}

There is broad consensus among experts that frailty is associated with worse outcomes after cardiac surgery. In the last year alone, there have been numerous studies devoted to the subject, providing evidence that frailty predicts greater mortality, greater resource use, and lower functional outcomes and even dictates the nature and location of discharge from the hospital. ${ }^{1-5}$ As a result, not only are select markers of frailty now incorporated into the Society of Thoracic Surgeons database, but groups are calling for more comprehensive preoperative frailty screening as a means to identify and triage patients at greatest risk. ${ }^{6}$ The challenge, of course, is there are either no universally accepted criteria for defining frailty, and established means involve cumbersome, time-consuming exercises or require specialized training and equipment.

In addition, despite the fact that most literature classifies patients into categories, including pre-frail and frail designations, ${ }^{5}$ it is increasingly accepted that frailty is more accurately described along a spectrum, with varying degrees of severity. It is in this context that Sarkar and colleagues $^{7}$ may provide additional clarity, having retrospectively evaluated patients undergoing cardiac surgery to develop a 20-point frailty score that incorporates binary risk variables across a host of patient-specific domains. Although these multifaceted rubrics are not necessarily novel ${ }^{8}$ - evidenced by the fact that the authors embellished upon a deficit-based model provided by others ${ }^{9}$ - the method offered by Sarkar and colleagues ${ }^{7}$ is particularly compelling because their results suggest that it is (1)

\footnotetext{
From the Departments of Anesthesiology and Critical Care Medicine and Surgery, The Johns Hopkins Medical Institutions, Baltimore, Md

Disclosures: Michael C. Grant reports he holds a nonremunerated position of influence, Executive Board Member-Enhanced Recovery After Surgery Cardiac Society.

The Journal policy requires editors and reviewers to disclose conflicts of interest and to decline handling or reviewing manuscripts for which they may have a conflict of interest. The editors and reviewers of this article have no conflicts of interest.

Received for publication Nov 3, 2021; revisions received Nov 3, 2021; accepted for publication Nov 12, 2021; available ahead of print Nov 29, 2021

Address for reprints: Michael C. Grant, MD, MSE, Johns Hopkins Hospital, 1800 Orleans St, Zayed 6208, Baltimore, MD 21287 (E-mail: mgrant17@jhmi.edu).

JTCVS Open 2021;8:503-4

2666-2736

Copyright (c) 2021 The Author(s). Published by Elsevier Inc. on behalf of The American Association for Thoracic Surgery. This is an open access article under the CC BY-NC-ND license (http://creativecommons.org/licenses/by-nc-nd/4.0/).

https://doi.org/10.1016/j.xjon.2021.11.009
}

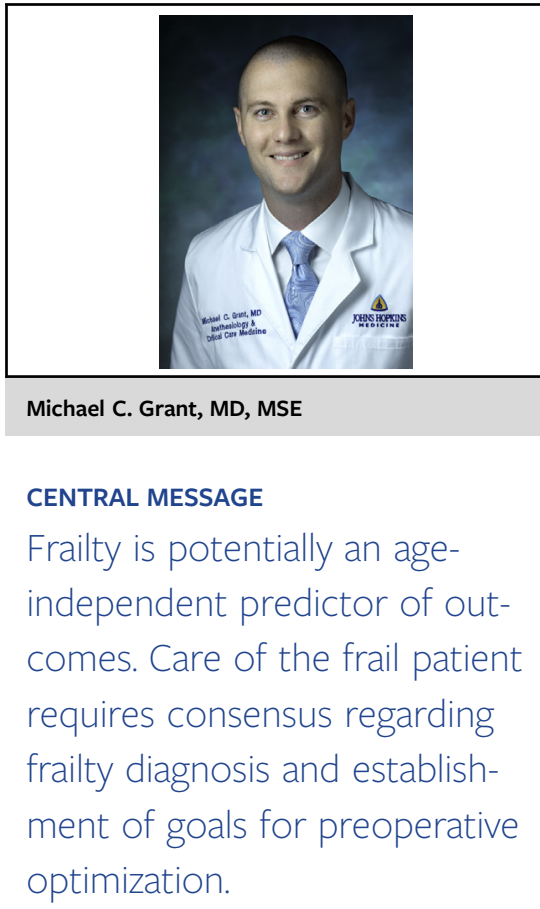

age-independent, which casts the first stone against the basic tenet that age is inextricably linked to frailty, highlighting that age alone is a poor surrogate for surgical outcome; and (2) computed from data readily available through existing electronic health records, akin to widely used cardiac risk scores (ie, Society of Thoracic Surgeons and European System for Cardiac Operative Risk Evaluation), which suggests it has greater practical application compared with more labor-intensive assessment strategies.

As with all medical inquiry, the 2 steps forward offered by this study are accompanied by a cautious step back. In analytics, any model such as the one put forward by Sarkar and colleagues ${ }^{7}$ is strengthened with additional data, allowing for improved internal validation and codification. However, as the authors admit, the model still requires prospective external validation through not only its application to separate patient cohorts, but also through comparison with existing frailty-assessment modalities. Further, any exercise that identifies a vulnerable population in advance of cardiac surgery should be coupled with targeted interventions to mitigate risk. To that end, fledgling examples of preoperative optimization (or "prehabilitation") have been focused on addressing individual modifiable risk factors, including preoperative anemia, sarcopenia, and exercise tolerance., ${ }^{6,10-12}$ However, in much the same fashion that preoperative risk assessment has expanded to acknowledge the many 
interrelated domains that contribute to the frailty diagnosis, preoperative optimization should be equally multifaceted, with protocols developed to comprehensively address highlighted deficits. Time will tell if more automated risk stratification can inform better care for our most vulnerable patients, but our growing understanding of frailty suggests that the old saying is true: age is only a number.

\section{References}

1. McIsaac DI, Fottinger A, Sucha E, McDonald B. Association of frailty with days alive at home after cardiac surgery: a population-based cohort study. $\mathrm{Br} J$ Anaesth. 2021;126:1103-10.

2. Bäck C, Hornum M, Jørgensen MB, Lorenzen US, Olsen PS, Møller CH, et al. Comprehensive assessment of frailty score supplements the existing cardiac surgical risk scores. Eur J Cardiothorac Surg. 2021;60:710-6.

3. Dobaria V, Hadaya J, Sanaiha Y, Aguayo E, Sareh S, Benharash P. The pragmatic impact of frailty on outcomes of coronary artery bypass grafting. Ann Thorac Surg. 2021;112:108-15.

4. Nakano M, Nomura Y, Suffredini G, Bush B, Tian J, Yamaguchi A, et al. Functional outcomes of frail patients after cardiac surgery: an observational study. Anesth Analg. 2020;130:1534-44.

5. Lee JA, Yanagawa B, An KR, Arora RC, Verma S, Friedrich JO; Canadian Cardiovascular Surgery Meta-Analysis Working Group. Frailty and pre-frailty in cardiac surgery: a systematic review and meta-analysis of 66,448 patients. $J$ Cardiothorac Surg. 2021;16:184.

6. Yanagawa B, Graham MM, Afilalo J, Hassan A, Arora RC. Frailty as a risk predictor in cardiac surgery: beyond the eyeball test. J Thorac Cardiovasc Surg. 2019;157:1905-9.

7. Sarkar S, MacLeod JB, Hassan A, Dutton DJ, Brunt KR, Légaré JF. An ageindependent hospital record-based frailty score correlates with adverse outcomes after heart surgery and increased health care costs. J Thorac Cardiovasc Surg Open. 2021;8:491-502.

8. Solomon J, Moss E, Morin JF, Langlois Y, Cecere R, de Varennes B, et al. The essential frailty toolset in older adults undergoing coronary artery bypass surgery. J Am Heart Assoc. 2021;10:e20219.

9. Eckart A, Hauser SI, Haubitz S, Struja T, Kutz A, Koch D, et al. Validation of the hospital frailty risk score in a tertiary 396 care hospital in Switzerland: results of a prospective, observational study. BMJ Open. 2019;9:e026923.

10. Waite I, Deshpande R, Baghai M, Massey T, Wendler O, Greenwood S. Homebased preoperative rehabilitation (prehab) to improve physical function and reduce hospital length of stay for frail patients undergoing coronary artery bypass graft and valve surgery. J Cardiothorac Surg. 2017;12:91.

11. Arthur HM, Daniels C, McKelvie R, Hirsh J, Rush B. Effect of a preoperative intervention on preoperative and postoperative outcomes in low-risk patients awaiting elective coronary artery bypass graft surgery: a randomized, controlled trial. Ann Intern Med. 2000;133:253-62.

12. Engelman DT, Ben Ali W, Williams JB, Perrault LP, Reddy VS, Arora RC, et al. Guidelines for perioperative care in cardiac surgery: Enhanced Recovery After Surgery Society Recommendations. JAMA Surg. 2019;154:755-66. 